«Системні технологіï» 6 (131) 2020 «System technologies»

DOI 10.34185/1562-9945-6-131-2020-15

УДК 669.162:004.942

А.М. Селегей, Т.В. Селівьорстова

\title{
МЕТОДИКА ВИЗНАЧЕННЯ ФАКТИЧНОГО РУДНОГО НАВАНТАЖЕННЯ ДОМЕННОЇ ПЕЧІ $З$ ДОПОМОГОЮ СПЕЦІАЛІЗОВАНОГО ПРОГРАМНОГО ЗАБЕЗПЕЧЕННЯ
}

Анотація. В роботі розроблено нову методику автоматизованого розрахунку фактичного рудного навантаження на колошнику доменної печі, що обладнана системою моніторингу поверхні засипу шихтових матеріалів. Рудне навантаження, що дорівнює відношенню маси залізовмісних шихтових матеріалів до маси палива (коксу) є важливим показником, що характеризує протікання доменного процесу. Корегування ходу плавки можливе завдяки зміні параметрів завантаження шихтових матеріалів на колошник, а це, в свою чергу, потребує проведення аналізу газодинамічних характеристик та відповідного фактичного значення рудного навантаження. Визначене фактичне рудне навантаження не тільки вздовж радіусу колошника, а й всієї доменної печі. Запропоновано новий підхід до корегування параметрів завантаження шихтових матеріалів в доменну піч, який базується на зміні рудного навантаження вздовж радіусу колошника. Це дозволяє впродовж визначеної кількості циклів завантаження досягти розподілення оптимального розподілення рудного навантаження, яке задається у вигляді функціональної залежності. Наведені напрямки подальших досліджень, що вдосконалюватимуть процес раціоналізації керуючих факторів завантаження для оперативної та якісної корекції процесу доменної плавки на конкретній печі та з використанням шихтових матеріалів 3 конкретними гранулометричними характеристиками.

Ключові слова: доменна піч, рудне навантаження, завантаження шихти, корекція, програмне забезпечення, радіально-кільцеві зони.

Вступ. Багато дослідників займались питанням автоматизації ведення доменної плавки. В цьому напрямку доволі багато досягнуто. Сьогодні ступінь автоматизації процесу завантаження шихтових матеріалів в доменну піч доволі низький. Це пов'язано перш за все з тим, що більшість доменних печей в Україні та за її межами не обладнані системою моніторингу поверхні засипу шихтових матеріалів на колошнику, яка б мала достатню точність [1-3]. 3 впровадженням радарної системи моніторингу поверхні засипу шихтових матеріалів на колошнику з'являється можливість отримання інформації фактичного розподілення шихтових матеріалів того чи іншого виду вздовж радіуса

(C) Селегей А.М., Селівьорстова Т.В., 2020 


\section{«Системні технології» 6 (131) 2020 «System technologies»}

колошника. Це дає змогу розрахувати фактичне рудне навантаження вздовж радіусу колошника та отримуючи інформацію щодо складу колошникового газу вздовж радіально кільцевих зон корегувати газодинамічний стан «сухої» зони доменної печі для досягнення більш ефективного протікання процесу відновлення заліза.

В наші дні практично всі інженерні розрахунки проводяться із застосуванням комп'ютерної техніки. При цьому, сфера розробки інженерного програмного забезпечення відокремилася в окрему IT-індустрію, яка працює на стику різних науково-технічних знань і дисциплін - математики, фізики, електроніки, програмування. Цей міждисциплінарний підхід в повній мірі поєднує в собі ідеї STEM (science, technology, engineering, mathematics).

Рудне навантаження є одним з основних показників доменної плавки. Воно являє собою відношення маси залізорудної частини доменної шихти до коксової частини. Рудне навантаження змінюється вздовж радіуса колошника доменної печі. За зміною цього показника судять про режим завантаження і може бути проведена корекція програми завантаження доменної печі [2]. Даний розрахунок досить складний, тому розробка спеціалізованого програмного забезпечення для визначення завантаження доменної печі $є$ актуальною задачею.

Аналіз стану питання. Розрахунку рудного навантаження присвячено велику кількість досліджень [1-3]. доведено, що зміною цього показника можна ефективно впливати на фізико-хімічні процеси, що протікають у товщі шихтових матеріалів, що знаходяться у доменній печі.

Одним з основних недоліків існуючих методик визначення рудного навантаження на колошнику доменної печі $\epsilon$ те, що значення мас компонентів шихтових матеріалів, що використовуються при розрахунку визначаються суто теоретичними методами. Наприклад, у разі використання інженерної методики Інституту чорної металургії НАН України рудне навантаження у радіально-кільцевих зонах (РКЗ) визначають за допомогою значень мас, які завантажуються у конкретну РКЗ на основі теоретичного розрахунку траєкторії шихтових матеріалів, що зсипаються з лотка-розподільника безконусного завантажувального пристрою. Однак треба враховувати, що незначна зміна шихтових умов (наприклад гранулометричних характеристик матеріалу) призводить до зміни траєкторії шихти при використанні тих самих значень керуючих факторів (кута нахилу лотка-розподільника, ступеня відкриття шиберного затвору накопичувального бункеру). Невірні розраховані значення рудного на176 


\section{«Системні технологіï» 6 (131) 2020 «System technologies»}

вантаження призводять до хибних рішень по зміні параметрів програм завантаження доменної печі і, як наслідок, не досягнення бажаних результатів ефективності плавки в цілому.

3 розвитком техніки, що забезпечує контрольні та вимірювальні функції моніторингу доменного процесу, зокрема впровадженням радарної системи стеження у реальному часі за рельєфом поверхні засипу шихтових матеріалів на колошнику, з'являється можливість визначення фактичного рудного навантаження, що дає можливість оперативно та ефективно корегувати хід доменної плавки.

Для того щоб визначити фактичне рудне навантаження по радіусу колошника, його умовно розбивають на десять рівновеликих по площі зон. Ці зони називаються радіально-кільцевими зонами колошника доменної печі. Для визначення рудного навантаження в кожній радіально кільцевої зоні колошника необхідно знати кількість матеріалу та його масу, що завантажується в неї. На сьогоднішній день відома інженерна методика для визначення рудного навантаження в кільцевої зоні. Вона являє собою теоретичний розрахунок траєкторії шихтових матеріалів що зсипають з лотка-розподільника безконусного завантажувального пристрою доменної печі. На підставі даного розрахунку визначають, скільки по масі залізорудного матеріалу і коксу завантажено в ту чи іншу радіально-кільцеву зону колошника. Однак зміна шихтових умов ведення доменної плавки викликає зміни траєкторії. Обчислення траєкторії $є$ досить трудомістким процесом. У зв'язку з цим оперативно реагувати на зміну шихтових умовах при розрахунку рудної навантаження досить складно. Тому запропонована нова методика для визначення частинних і загальних рудних навантажень, заснована на показниках радарних датчиків рівня розташованих на куполі колошника доменної печі. Записуючи свої рівні засипання шихтових матеріалів можливе визначення їх об'ємів. 3 огляду на насипну щільність даних матеріалів можна обчислити фактичну масу. Знаючи ці параметри неважко обчислити фактичну рудню навантаження доменної печі [3].

На рисунку 1 показаний поперечний перетин доменної печі, розділений на десять радіально-кільцевих зон. 3 використанням радарних датчиків рівня були отримані значення заповнення доменної печі агломератом та коксом. Данні рівня зняті в чотирьох точках кожної зони по квадрантах. Таким чином кожного разу за допомогою радарних датчиків рівня визначають значення 
«Системні технології» 6 (131) 2020 «System technologies»

40-х точок рівня. В таблиці 1 показані данні, які характеризують рівень заповнення доменної печі перед та після засипання однієї з десяти порцій.

Слід зазначити, що радіуси радіально-кільцевих зон визначені таким чином, що площі перетину РКЗ були рівними.

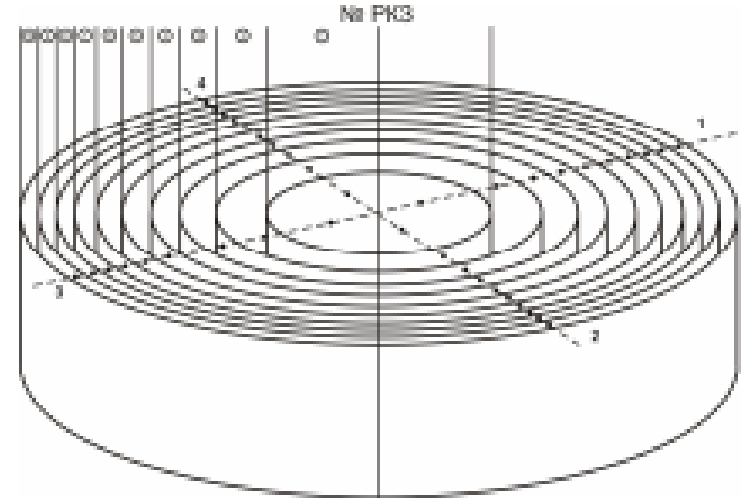

Рисунок 1 - Схема розташування радіально-кільцевих зон на колошнику доменної печі

Товщина шару заданої точки кільцевої зони дорівнює:

$$
h_{i}=\left(U_{\mathrm{i}}^{\text {кон }}-U_{i}^{\text {нач }}\right)+\mathrm{V}_{\mathrm{cx}} \cdot t,
$$

де $U_{i}^{\text {нач }}$ - відстань до поверхні засипу перед вивантаженням порції; $\mathrm{U}_{\mathrm{i}}^{\text {кон }}$ - відстань до поверхні засипу після вивантаження порції; $\mathrm{V}_{\mathrm{cx}}$ - швидкість опускання шихти в печі, приймаємо рівною 0.13 м/хв.; $t$ - час засипання порції, приймаємо рівним 1 хвилині.

Середня товщина шару у кожній кільцевій зоні дорівнює:

$$
h_{c p}=\frac{h_{1}+h_{2}+h_{3}+h_{3}}{4} \text {. }
$$

Об’єм шихтових матеріалів при вивантаженні однієї порції:

$$
V=\frac{\pi h_{c p}}{4}\left(D^{2}-d^{2}\right)
$$

де $D$ - зовнішній діаметр кільцевої зони, $d$ - внутрішній діаметр кільцевої зони.

Маса шихти у кільцевій зоні:

$$
m=\gamma V=\frac{\gamma \pi h_{c p}}{4}\left(D^{2}-d^{2}\right)
$$

де $\gamma_{A}=2 \mathrm{~T} / \mathrm{M}^{3}, \gamma_{k}=0,5 \mathrm{~T} / \mathrm{M}^{3}-$ насипна маса агломерату і коксу.

Рудне навантаження необхідно порахувати для циклу, що складається з 10 подач [2]. Узагальнена схема обчислення фактичного рудного навантаження доменної печі зображена на рисунку 2 та обчислюється по формулі: 
«Системні технологіï» 6 (131) 2020 «System technologies»

$$
R=\frac{\xi \sum_{1}^{10} \frac{R_{i} \delta_{i}}{\xi+R_{i}}}{1-\sum_{1}^{10} \frac{R_{i} \delta_{i}}{\xi+R_{i}}},
$$

де $\xi=\frac{\gamma_{A}}{\gamma_{k}}, R_{i}=\frac{m_{A}}{m_{k}} \cdot m_{A}-$ маса агломерату, $m_{k}-$ маса коксу, $\delta$ - задається для кожної подачі в частках, $\delta=0,1$.

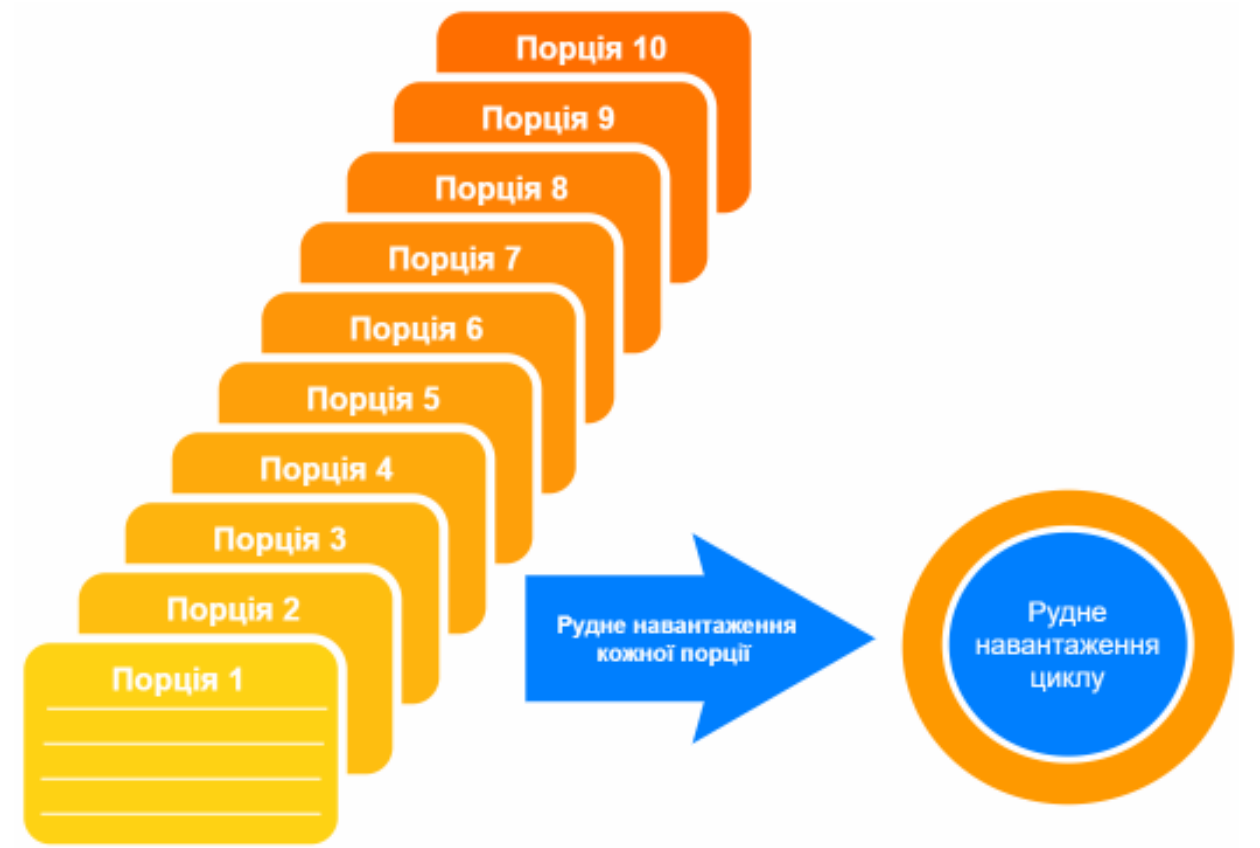

Рисунок 2 - Схема обчислення фактичного рудного навантаження доменної печі

Таблиця 1

Вихідні дані для розрахунку рудного навантаження доменної печі

\begin{tabular}{|l|l|l|l|l|l|l|l|l|}
\hline \multicolumn{7}{|c|}{ Порція № 1, кокс } \\
\hline № РК3 & $U_{1}^{0}$ & $U_{1}^{1}$ & $U_{2}^{0}$ & $U_{2}^{1}$ & $U_{3}^{0}$ & $U_{3}^{1}$ & $U_{4}^{0}$ & $U_{4}^{1}$ \\
\hline 1 & 0,91 & 0,9 & 0,82 & 0,8 & 1,9 & 1,1 & 1,5 & 0,8 \\
\hline 2 & 0,66 & 0,65 & 0,76 & 0,74 & 1,4 & 0,8 & 1,245 & 0,778 \\
\hline 3 & 0,68 & 0,6 & 0,75 & 0,68 & 0,95 & 0,75 & 1,1 & 0,8 \\
\hline 4 & 1 & 0,665 & 0,666 & 0,59 & 0,81 & 0,7 & 1 & 0,79 \\
\hline 5 & 1,8 & 0,65 & 0,715 & 0,568 & 0,845 & 0,71 & 0,9 & 0,84 \\
\hline 6 & 1,5 & 0,85 & 0,78 & 0,6 & 0,8 & 0,72 & 0,83 & 0,8 \\
\hline 7 & 1,5 & 1 & 0,9 & 0,6 & 0,83 & 0,82 & 0,78 & 0,75 \\
\hline 8 & 1,5 & 1,2 & 1 & 0,75 & 1,02 & 1 & 0,65 & 0,6 \\
\hline 9 & 1,5 & 1,71 & 1,09 & 0,84 & 1,03 & 1 & 0,59 & 0,56 \\
\hline 10 & 1,55 & 1,46 & 1,2 & 0,96 & 1,1 & 0,998 & 0,55 & 0,508 \\
\hline
\end{tabular}


«Системні технології» 6 (131) 2020 «System technologies»

Метою роботи $є$ програмна реалізація методики визначення рудного навантаження запропонованої авторами роботи у вигляді модулю спеціалізованого програмного забезпечення, а також розробка наукових основ для корекції розподілення рудного навантаження в конкретній доменній печі з конкретними шихтовими умовами.

Основний матеріал. Для виконання програмної реалізації було обрано середовище C++ Builder. Додаток має назву «Blast_Furnace_Loading» - «Завантаження доменної печі».

Розглянемо приклад роботи додатку «Blast_Furnace_Loading» на даних 3 таблиці 1. Необхідно запустити додаток Project_Blast_Furnace_Loading.exe (рисунок 3).

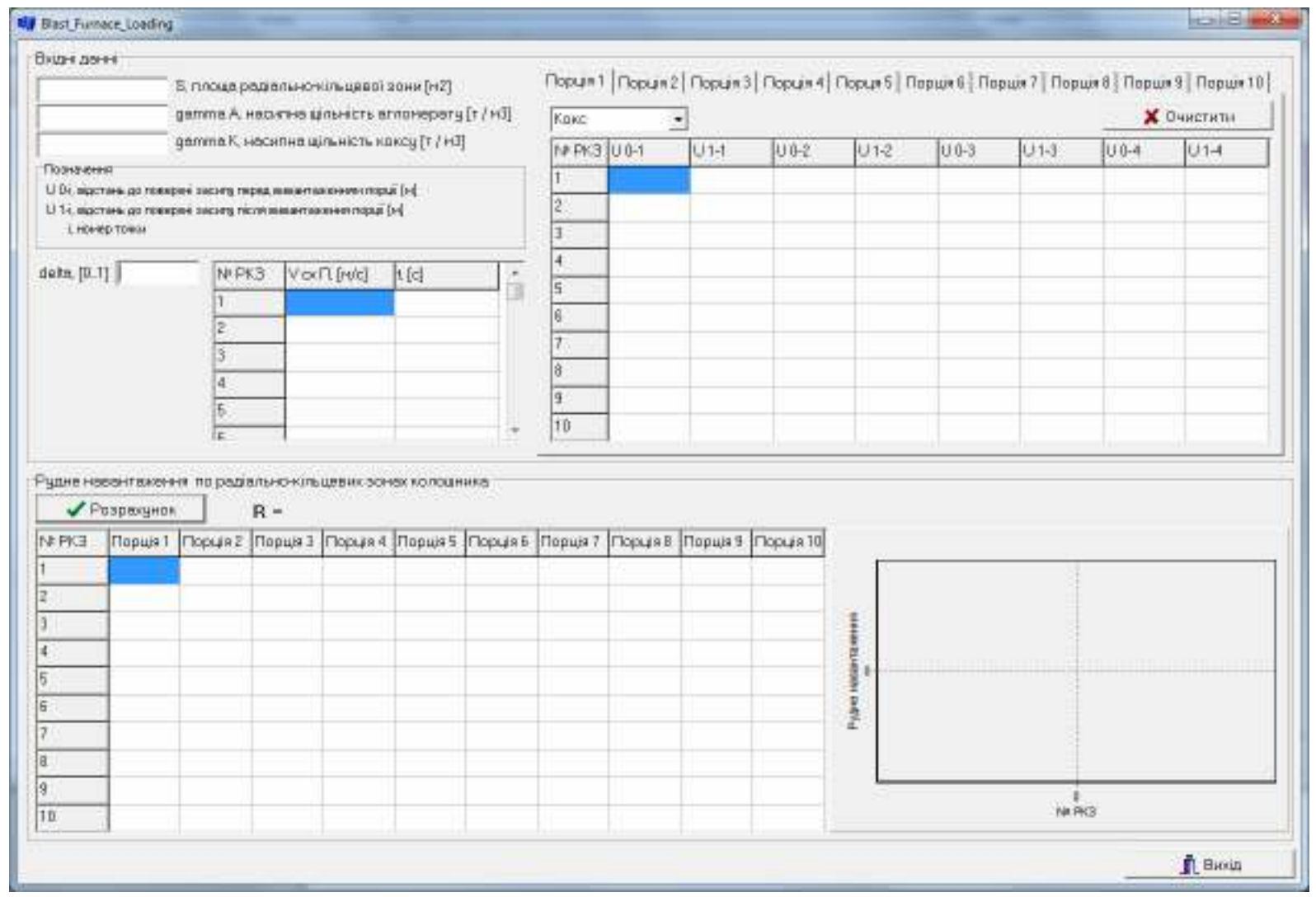

Рисунок 3 - Додаток «Blast_Furnace_Loading» готовий до роботи

Уважно вводимо дані (рисунок 4). В якості роздільника цілої та дробової частини використовуємо точку. 
«Системні технологіï» 6 (131) 2020 «System technologies»

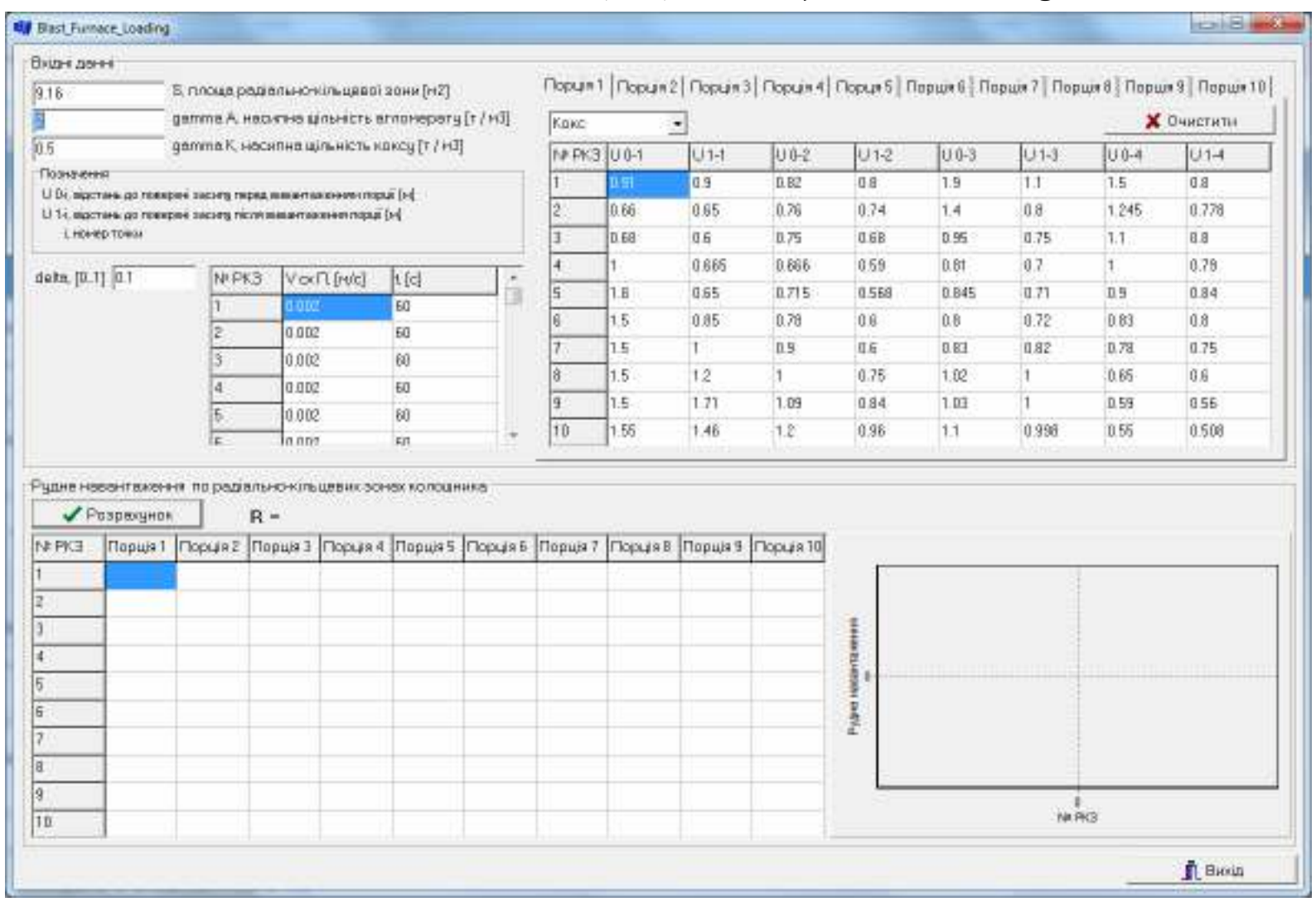

Рисунок 4 - Додаток «Blast_Furnace_Loading», введені данні

Після натиснення на кнопки «Розрахунок» в таблицю були занесені значення маси коксу або агломерату, рудне навантаження для кожної кільцевої зони, загальне рудне навантаження доменної печі.

Таким чином, отримані дані дають змогу мати інформацію щодо фактичного розподілення шихтових матеріалів. Поєднуючи ці дані та інформацію щодо газодинаміки колошникової зони виникає можливість перерозподілу компонентів шихти для підвищення ефективності процесу відновлення заліза в доменній печі.

Маючи дані про шихтові та дуттьові умови плавки можна побудувати бажану графічну залежність рудного навантаження вздовж радіусу колошника. На рисунку 6 представлені раціональні та фактичні розподілення рудного навантаження вздовж радіусу колошника доменної печі. 
«Системні технологіï» 6 (131) 2020 «System technologies»

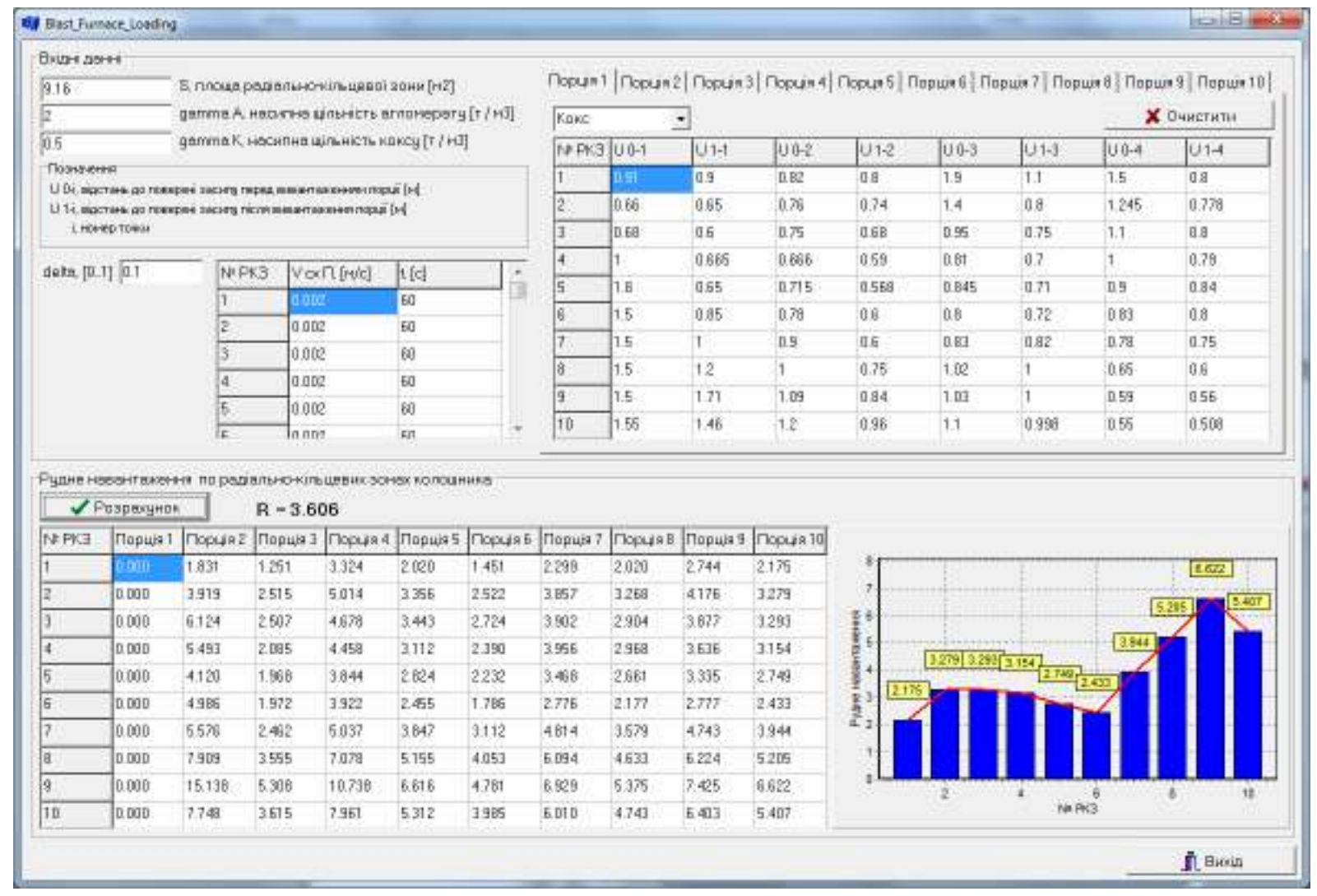

Рисунок 5 - Додаток «Blast_Furnace_Loading», результат обчислення рудного навантаження

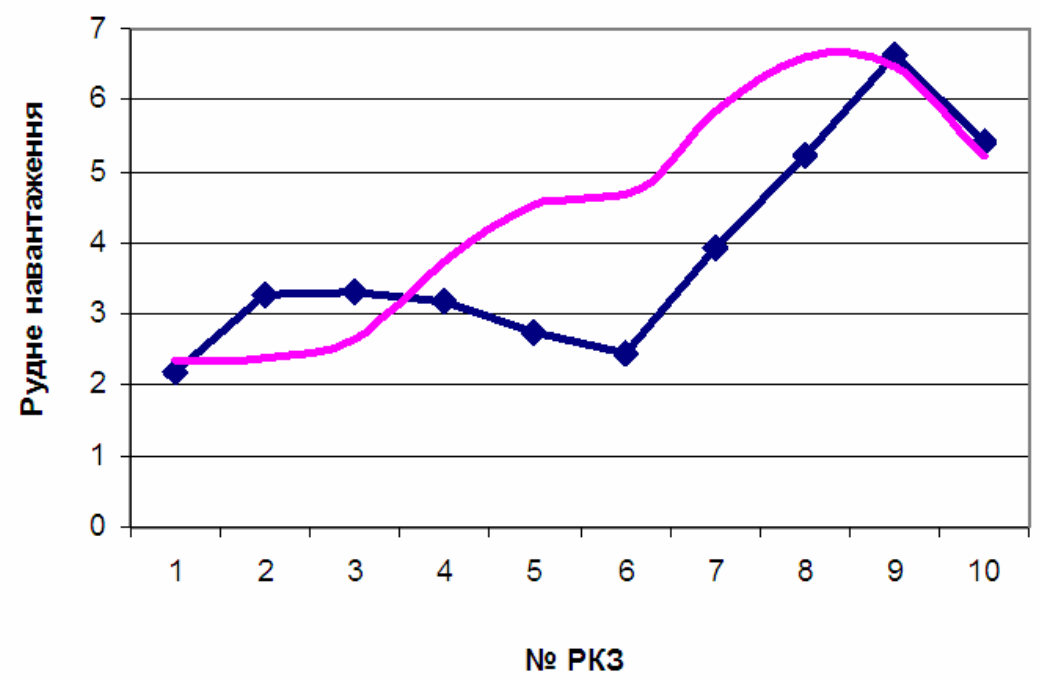

Рисунок 6 - Раціональне (фіолетова крива) та фактичне (синя крива) розподілення рудного навантаження вздовж радіусу колошника

Аналізуючи графічні залежності, що представлені на рисунку 5 можна зробити висновок, що існує можливість довантажити залізовмісними шихтовими матеріалами РК3 №№4-9. Також використовуючи різницю між фактич- 


\section{«Системні технологіï» 6 (131) 2020 «System technologies»}

ним і бажаним розподіленням визначається конкретна кількість та вид шихтового матеріалу, що завантажується у піч.

Дана робота виконувалась сумісно з кафедрою інформаційних технологій та систем Національної металургійної академії України. Результати отримані iз застосування додатку «Blast_Furnace_Loading» відповідають теоретичним розрахункам.

Висновки. В роботі отримані нові наукові дані, які дають можливість визначати фактичне рудне навантаження вздовж радіусу колошника доменної печі. Використання цих матеріалів дозволить оперативно та ефективно проводити корекцію ходу доменного процесу та економити енергоресурси за рахунок раціонального завантаження шихтових матеріалів.

\section{ЛІТЕРАТУРА / ЛИТЕРАТУРА}

1. Большаков В. И. Технология высокоэффективной энергосберегающей доменной плавки / Большаков В. И. - К.: Наук. думка, 2007. - 412 с.

2. Использование информации профилемера для выбора управляющих воздействий на ход доменной плавки / [Большаков В. И., Муравьева И. Г., Семенов Ю. С., Шулико С. Т., Листопадов В. С., Дмитренко К. А., Орел Г. И.] - «Черметинформация». Бюллетень «Черная металлургия», 2006. - № 5. - С. 29-34.

3. Большаков В. И. Новые металлургические технологии и научно-технические разработки Института черной металлургии в 2007 году / Большаков В. И., Жучков С. М., Муравьева И. Г. - Труды IV Международной конференции «Стратегия качества в промышленности и образовании». Том 1. Варна, Болгария, 2008. C. 14-28.

\section{REFERENCES}

1. Bolshakov V. I. Technology of highly efficient energy-saving blast furnace melting / Bolshakov V. I. - K .: Nauk. Dumka, 2007 .-- 412 p.

2. Using the information of the profiler to select control actions on the course of blast-furnace smelting / [Bolshakov V. I., Muravyova I. G., Semenov Yu. S., Shuliko S. T., Listopadov V. S., Dmitrenko K. A. , Orel G. I.] - "Chermetinformation". Bulletin "Ferrous metallurgy", 2006. - No. 5. - P. 29-34.

3. Bolshakov V. I. New metallurgical technologies and scientific and technical developments of the Institute of Ferrous Metallurgy in 2007 / Bolshakov V. I., Zhuchkov S. M., Muravyova I. G. - Proceedings of the IV International Conference "Strategy of quality in industry and education ". Volume 1. Varna, Bulgaria, 2008. P. 14-28. 


\section{«Системні технології» 6 (131) 2020 «System technologies»}

\section{Методика визначення фактичного рудного навантаження доменної печі з допомогою спеціалізованого програмного забезпечення}

В роботі розроблено нову методику автоматизованого розрахунку фактичного рудного навантаження на колошнику доменної печі, що обладнана системою моніторингу поверхні засипу шихтових матеріалів. Рудне навантаження, що дорівнює відношенню маси залізовмісних шихтових матеріалів до маси палива (коксу) є важливим показником, що характеризує протікання доменного процесу. Корегування ходу плавки можливе завдяки зміні параметрів завантаження шихтових матеріалів на колошник, а це, в свою чергу, потребує проведення аналізу газодинамічних характеристик та відповідного фактичного значення рудного навантаження. Визначене фактичне рудне навантаження не тільки вздовж радіусу колошника, а й всієї доменної печі. Запропоновано новий підхід до корегування параметрів завантаження шихтових матеріалів в доменну піч, який базується на зміні рудного навантаження вздовж радіусу колошника. Це дозволяє впродовж визначеної кількості циклів завантаження досягти розподілення оптимального розподілення рудно20 навантаження, яке задається у вигляді функціональної залежності. Наведені напрямки подальших досліджень, що вдосконалюватимуть процес раціоналізації керуючих факторів завантаження для оперативної та якісної корекції процесу доменної плавки на конкретній печі та з використанням шихтових матеріалів з конкретними гранулометричними характеристиками.

\section{Prospects for the use of integrated technologies of gas-dynamic impact on the melt in the mold}

Trends in expanding the range of steel ingots, instability and crushing of orders at existing foundries that do not have additional specialized equipment, high capital costs for global technical re-equipment, necessitate the search for new technological ways to obtain quality products. Therefore, more and more attention of scientists and practitioners is attracting questions related to improving existing and developing new processes to improve the quality of cast metal, reduce the cost of producing products, and increase the degree of environmental friendliness of production in general. One of such recognized ways to improve the quality of cast billets is the use of external physical effects on the liquid metal, and the metal that crystallizes directly in the mold (mold).

The paper presents an analysis of scientific and technical information on the use of out-offurnace processing processes and the use of gas pressure to improve the quality of cast metal of large castings or ingots. The prospects of using these effects for processing the melt directly in the mold (mold) is shown. The possibility of implementing a process of complex in-situ gasdynamic impact on the melt of large castings and ingots, which consists of sequential inert gas blowing through a siphon sprue system, evacuation and subsequent gas-dynamic pressure in the solidification process using the appropriate devices. Specific options for their design and technological features of the work are determined.

A distinctive feature of the technology is that during the entire process from the onset of solidification, the metal is affected by the creation of an adjustable gas pressure in a sealed 
«Системні технологіï» 6 (131) 2020 «System technologies»

casting-gas injection system. The proposed device is structurally simple and can be easily integrated into an existing process without the need for significant capital costs.

The need for further research to develop a common methodology for determining the duration of the purge, and rational modes of intra-molten melt evacuation of the sealed casting system - a device for gas-dynamic effects.

Селиверстова Татьяна Витальевна - к.т.н., доцент, доцент кафедры информационных технологий и систем, Национальная маталлургическая академия Украины, ORCID 0000-0002-2470-6986.

Селегей Андрей Николаевич - к.т.н., доцент, доцент кафедры прикладной механики, Национальная металлургическая академия Украины.

Селівьорстова Тетяна Віталіївна - к.т.н., доцент, доцент кафедри інформаційних технологій та систем, Національна металургійна академія України, ORCID 0000-0002-2470-6986.

Селегей Андрій Миколайович - к.т.н., доцент, доцент кафедри прикладної механіки, Національна маталургійна академія України.

Selivyorstova Tatjana - candidate of technical science, assistant professor, Department of information technology and systems, The National Metallurgical Academy of Ukraine, ORCID 0000-0002-2470-6986.

Selegej Andriy - candidate of technical science, assistant professor, Department of Applied mechanics, The National Metallurgical Academy of Ukraine. 